\title{
NEURITIS ÓPTICA PARANEOPLÁSICA EN CARCINOMA MICROCÍTICO PULMONAR DESCONOCIDO DEFINIDA POR MARCADOR CRMP-5-IgG
}

\section{PARANEOPLASTIC OPTIC NEURITIS IN AN UNKNOWN SMALL CELL LUNG CARCINOMA DEFINED BY CRMP-5-IgG}

\author{
TORIBIO-GARCÍA JA ${ }^{1}$, FRANCO-BENITO M${ }^{1}$, GARCÍA-RUIZ-DE-MORALES JM ${ }^{2}$
}

\section{RESUMEN}

Caso clínico: Se presenta el caso de un paciente de 64 años con disminución de agudeza visual bilateral, progresiva e indolora. La exploración oftalmológica reveló papilitis con vitritis en ambos ojos, en distinto estadio. Con la sospecha de neuritis óptica paraneoplásica se solicitó estudio de autoanticuerpos que mostró positividad al marcador CRMP-5IgG. Tras realizar mediastinoscopia, se diagnosticó un carcinoma microcítico pulmonar.

Discusión: El autoanticuerpo CRMP-5-IgG define una entidad paraneoplásica consistente en neuritis óptica con vitritis. La serología positiva evita la biopsia vítrea y agiliza la búsqueda del cáncer. En nuestro caso permitió el diagnóstico de un tumor que era desconocido.

Palabras clave: Neuritis óptica, paraneoplásica, microcítico, CRMP-5-IgG.

\begin{abstract}
Case report: The case of a 64-year-old patient with bilateral, progressive and painless diminution of visual acuity is presented. Ophthalmologic evaluation revealed optic neuritis and vitreous cells in both eyes, at different stages. Suspecting a paraneoplastic optic neuritis, the study of antibodies was requested. This showed positivity to the marker CRMP-5-IgG. After mediastinoscopy, a small cell lung carcinoma was diagnosed.

Discussion: Autoantibody CRMP-5-IgG defines a paraneoplastic entity of combined optic neuritis and vitreous inflammatory cells. The serological positivity avoids the vitreous biopsy and expedites the search for cancer. In our case, it allowed the diagnosis a previously unidentified tumor (Arch Soc Esp Oftalmol 2007; 82: 777-780).
\end{abstract}

Key words: Optic neuritis, paraneoplastic, small cell, CRMP-5-IgG.

\footnotetext{
Recibido: 3/10/06. Aceptado: 17/9/07.

Hospital de León. León. España.

1 Licenciado en Medicina.

2 Doctor en Medicina. Inmunólogo clínico.

Comunicación presentada en la XIX Reunión Nacional del G.E.M.U. (Barcelona 2006). 


\section{INTRODUCCIÓN}

La pérdida de visión subaguda con papilitis y células en vítreo supone un problema diagnóstico ya que los hallazgos son en muchas ocasiones idénticos para las distintas etiologías posibles: isquémica, infecciosa, infiltrativa, desmielinizante o paraneoplásica.

Los síndromes neurológicos paraneoplásicos se definen como síndromes neurológicos de causa desconocida que a menudo preceden al diagnóstico de un tumor subyacente. En las últimas dos décadas, el descubrimiento de que muchos de los síndromes paraneoplásicos están asociados a la existencia de anticuerpos contra antígenos expresados por el tumor, sugiere que algunos de estos síndromes son inmuno-mediados (1). En este sentido, se han descrito dos autoanticuerpos que permiten definir dos de los síndromes paraneoplásicos con afectación ocular más importantes: la Retinitis Asociada a Cáncer (CAR) cuyo marcador es el CAR-IgG contra la proteína recoverina, y la Neuritis Asociada a Cáncer, cuyo marcador es el CRMP-5-IgG (también denominado anti CV2), contra la proteína mediadora de la respuesta de la colapsina (2).

\section{CASO CLÍNICO}

Varón de 64 años que refería pérdida de visión bilateral, progresiva e indolora, que afectaba a ojo izquierdo (OI) desde hacía 7 días y que en las últimas 48 horas había comenzado a afectar también al ojo derecho (OD). Como antecedentes destacaban ser un fumador importante y el fallecimiento de un hermano por neoplasia pulmonar. En la exploración oftalmológica encontramos una agudeza visual corregida de 0,4 en OD y movimiento de manos en OI. La presión intraocular y el segmento anterior eran normales, apreciándose en la funduscopia una vitritis moderada en ambos ojos, con ligera hiperemia de la papila de OD, y palidez papilar en OI (fig. 1). Se decidió ingreso para estudio, con el diagnóstico inicial de papilitis con vitritis bilateral.

La exploración neurológica, así como el hemograma y la bioquímica fueron normales. En la radiografía de tórax se observaba un leve engrosamiento del hilio pulmonar derecho (fig. 2), siendo el TAC craneal normal. La punción lumbar únicamente mostró una discreta elevación de las proteínas. Con estos datos se decidió iniciar tratamiento con bolos de corticoides y antiagregación.

En la angiofluoresceingrafía aparecía hipercaptación en papila sin signos de vasculitis. Los potenciales evocados fueron normales en OD y compatibles con una neuropatía axonal en OI. El electrorretinograma y la resonancia magnética cerebral fueron normales. La serología, inmunología y marcadores tumorales habituales fueron negativos.

Con las pruebas obtenidas, se descartó una etiología infecciosa, vascular o desmielizante, por lo que se valoró una etiología infiltrativa, o bien un

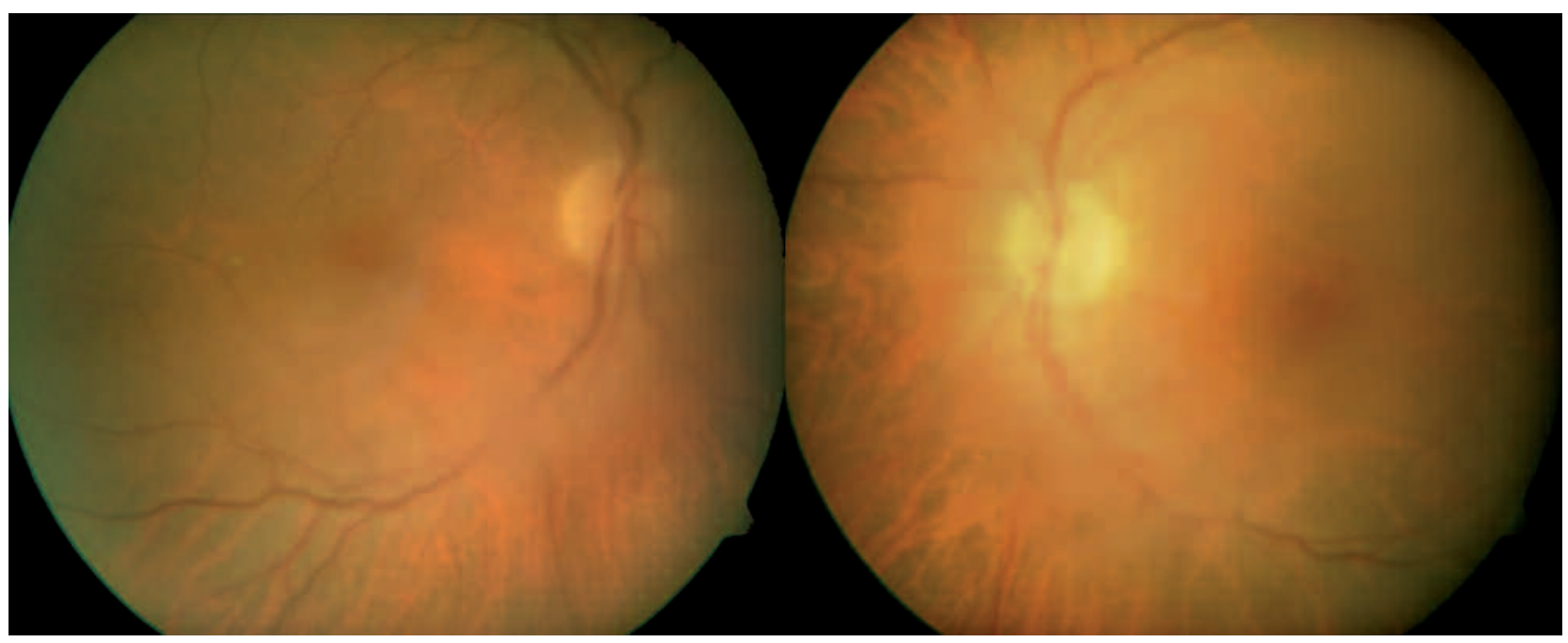

Fig. 1: Aspecto inicial del fondo ocular. Destaca la vitritis bilateral con hiperemia en papila de ojo derecho y palidez papilar en ojo izquierdo. 


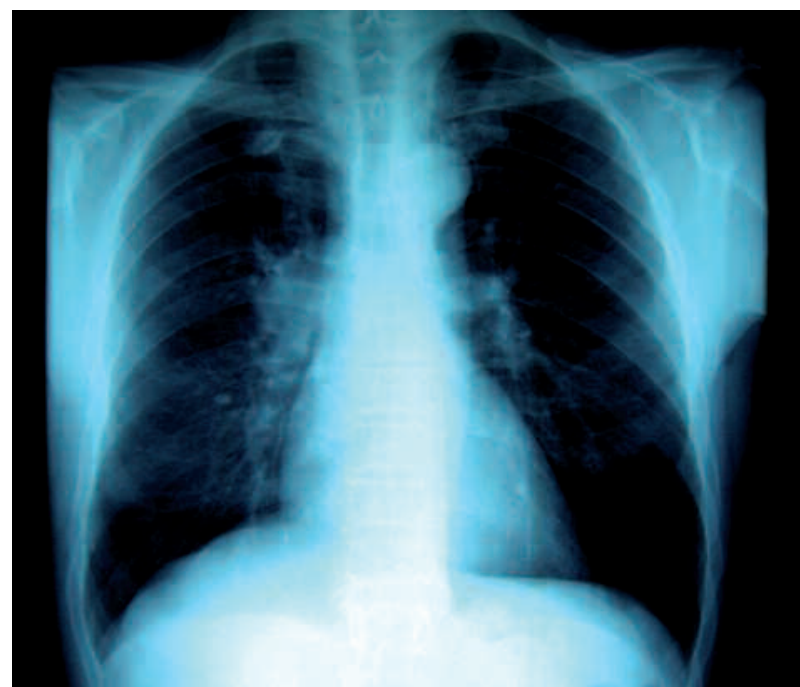

Fig. 2: Radiografía de tórax con discreto engrosamiento de hilio derecho.

síndrome paraneoplásico. Se solicitó un TAC tóraco-abdominal que mostraba una imagen de $3 \mathrm{~cm}$ en hilio derecho, compatible con adenopatía (fig. 3). La broncoscopia informó de un ensanchamiento de la carina, siendo la citología negativa para malignidad. Se planteó realizar un estudio PET para valorar mejor la adenopatía y remitir a Cirugía Torácica para practicar una mediastinoscopia. Además, se extrajeron muestras de líquido cefalorraquídeo, plasma y humor acuoso para estudiar el autoanticuerpo CRMP-5-IgG, que resultó positivo en las

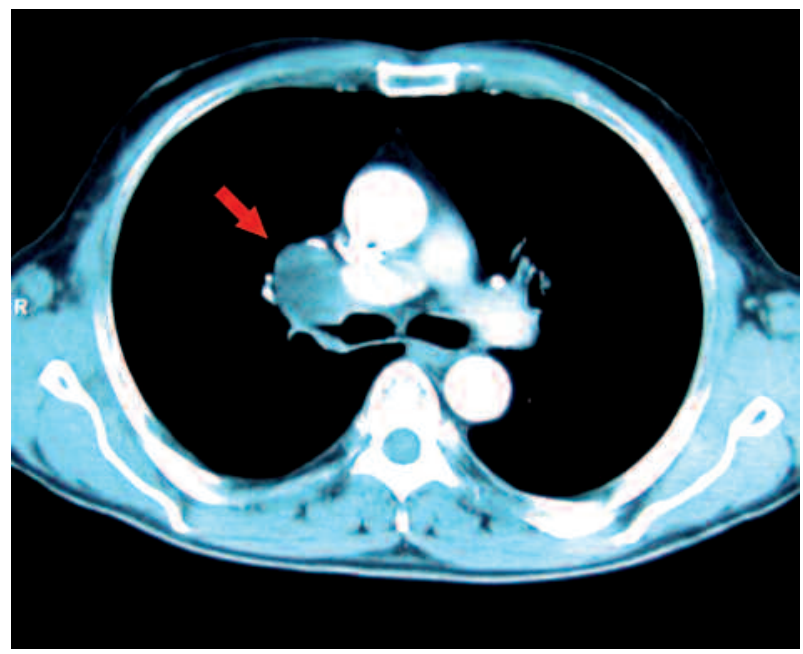

Fig. 3: TAC torácico en donde se aprecia una masa en hilio derecho (flecha). dos primeras. La positividad al CRMP-5-IgG y la presencia de neuritis se asocia en un $62,5 \%$ de los casos con la existencia de un carcinoma microcítico de pulmón $(2,3)$.

Con estos datos se decidió anular el estudio PET y realizar mediastinoscopia que se informó como carcinoma microcítico de pulmón. El Servicio de Oncología lo clasificó como carcinoma microcítico en estadío limitado, iniciando tratamiento con quimio y radioterapia.

La respuesta inicial al tratamiento corticoideo fue buena, mejorando la visión a 0,7-0,3 a los 15 días y alcanzando una agudeza visual final a los seis meses, cuando consideramos cerrado el estudio, de 0,8 en OD y 0,6 en OI, con una restitución ad integrum de la imagen funduscópica (fig. 4).

\section{DISCUSIÓN}

Los síndromes paraneoplásicos aparecen en menos del 1\% de los pacientes con cáncer. El tumor responsable con mayor frecuencia es el microcítico de pulmón. Se piensa que este tumor procede de las células de Kultschitzky de origen neuroectodérmico, y que en su crecimiento pueden expresar antígenos presentes en células nerviosas o que reaccionan de forma cruzada con antígenos del sistema nervioso, lo que estimula la producción de autoanticuerpos (4). Este es el caso del anti-CRMP-5-IgG cuya molécula diana es la proteína mediadora de la respuesta a la colapsina, fosfoproteína citosólica altamente expresada durante el desarrollo del sistema nervioso y cuya expresión aparece reducida en el adulto a algunas subpoblaciones de oligodendrocitos y células de Schwann (5). El tratamiento corticoideo frena la producción de autoanticuerpos y hace revertir la neuritis óptica.

Este marcador sólo aparece en un $0,17 \%$ de pacientes con clínica neurológica, mientras que de los pacientes CRMP-5-IgG positivos, únicamente un $7 \%$ presentan neuritis (3). La asociación de este marcador en plasma sanguíneo y neuritis óptica supone un $93 \%$ de probabilidades de presentar un tumor maligno, que si existe, en un $66 \%$ de los casos se trata de un carcinoma microcítico de pulmón (2).

La serología positiva evita la necesidad de biopsia vítrea y agiliza la búsqueda del cáncer, y en nuestro caso permitió el diagnóstico de un tumor que hasta el momento era desconocido. 


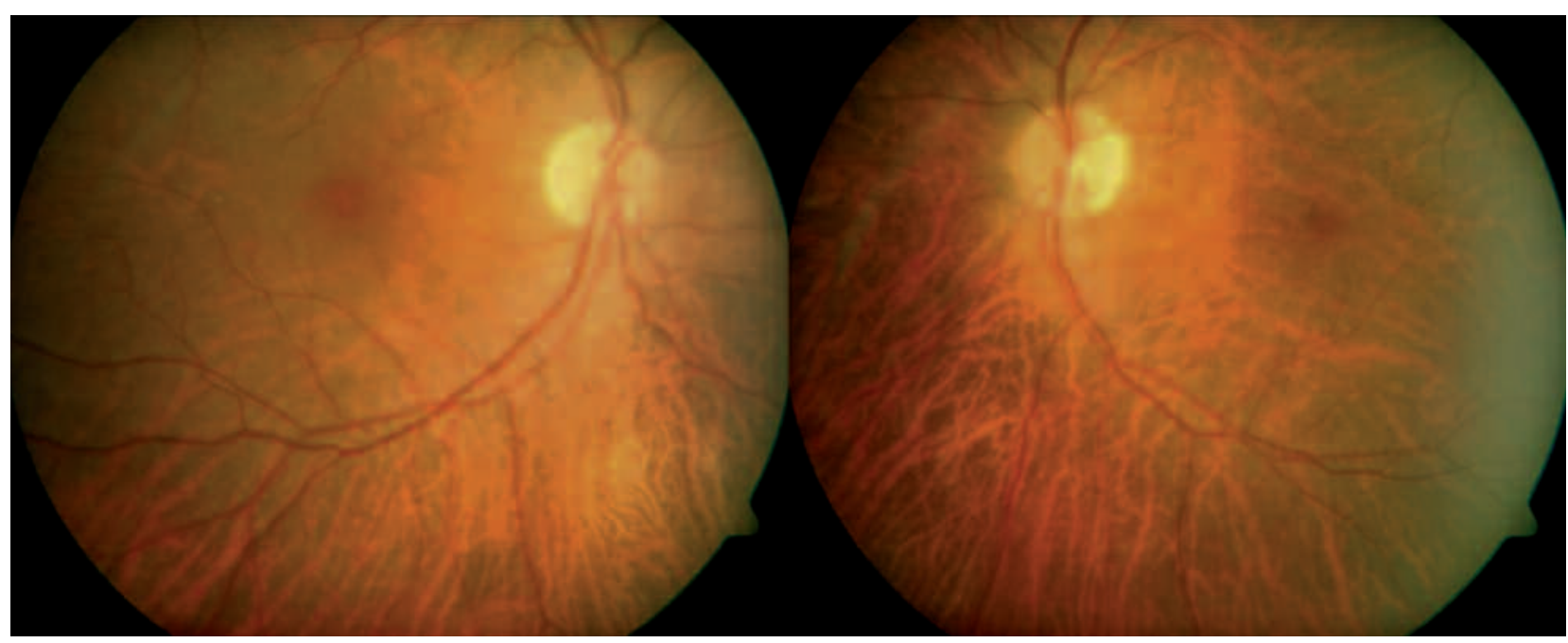

Fig. 4: Aspecto del fondo ocular a los seis meses, sin hallazgos significativos.

\section{BIBLIOGRAFÍA}

1. Weleber RG, Watzke RC, Shults WT, Trzupek KM, Heckenlively JR, Egan RA, et al. Clinical and electrophysiologic characterization of paraneoplastic and autoimmune retinopathies associated with antienolase antibodies. Am J Ophthalmol 2005; 139: 780 794.

2. Cross SA, Salomao DR, Parisi JE, Kryzer TJ, Bradley EA, Mines JA, et al. Paraneoplastic autoimmune optic neuritis with retinitis defined by CRMP-5-IgG. Ann Neurol 2003; 54: $38-50$.
3. Yu Z, Kryzer TJ, Griesmann GE, Kim K, Benarroch EE, Lennon VA. CRMP-5 neuronal autoantibody: marker of lung cancer and thymoma-related autoimmunity. Ann Neurol 2001; 49: 146-154.

4. Livingston PO, Ragupathi G, Musselli C. Autoimmune and antitumor consequences of antibodies against antigens shared by normal and malignant tissues. J Clin Immunol 2000; 20: 85-93.

5. PNSEURONET. Concerted Action on Paraneoplatic Neurological Syndromes. Anti-CV2 antibodies. [citado 17 Julio 2006]. Disponible en: http://www.pnseuronet.org/ professionals/antibody/cv2.html. 